\title{
Vaccination of mice with a recombinant novel cathepsin B inhibits Trichinella spiralis development, reduces the fecundity and worm burden
}

Jing Cui ${ }^{*}$, Yue Han, Xin Yue, Fang Liu, Yan Yan Song, Shu Wei Yan, Jun Jun Lei, Xi Zhang, Peng Jiang and Zhong Quan Wang ${ }^{*}$

\begin{abstract}
Background: Trichinella spiralis is a major zoonotic tissue-dwelling nematode, which is a public health concern and a serious hazard to animal food safety. It is necessary to exploit an anti-Trichinella vaccine to interrupt the transmission of Trichinella infection among animals and from animals to humans. The purpose of the present study was to characterize the novel T. spiralis cathepsin B (Ts $C B$ ) and to evaluate the immune protection elicited by immunization with recombinant TsCB (rTsCB).

Methods: The complete CDNA sequences of the TsCB gene were cloned, expressed and purified. The antigenicity of $\mathrm{rTS}$ CB was investigated by western blot analysis and ELISA. Transcription and expression of TSCB at various T. spiralis life-cycle stages were analyzed by RT-PCR and indirect immunofluorescent assay (IIFA). The mice were subcutaneously immunized with rTsCB, and serum level of TsCB-specific IgG (IgG1 and IgG2a) and IgE antibodies were assayed by ELISA. Immune protection elicited by vaccination with rTsCB was investigated.

Results: The TsCB was transcribed and expressed in four T. spiralis life-cycle stages (adult worm, AW; newborn larvae, NBL; muscle larvae, ML; and intestinal infective L1 larvae), it was primarily located in the cuticle and stichosome of the parasitic nematode. Vaccination of mice with rTsCB produced a prominent antibody response (high level of specific $\operatorname{lgG}$ and $\operatorname{lgE}$ ) and immune protection, as demonstrated by a $52.81 \%$ AW burden reduction of intestines at six days post-infection (dpi) and a 50.90\% ML burden reduction of muscles at $35 \mathrm{dpi}$ after oral larva challenge. The TsCB-specific antibody response elicited by immunization with rTsCB also impeded intestinal worm growth and decreased the female fecundity.
\end{abstract}

Conclusions: TsCB might be considered as a novel potential molecular target to develop vaccines against T. spiralis infection.

Keywords: Trichinella spiralis, Trichinellosis, Cathepsin B, Vaccination, Immune protection

\section{Background}

Trichinella spiralis is an important zoonotic tissuedwelling nematode, the largest intracellular parasite which infects more than 150 different kinds of

\footnotetext{
*Correspondence: cuij@zzu.edu.cn; jpdaisy@126.com; wangzq2015@126.com

Department of Parasitology, Medical College, Zhengzhou University, Zhengzhou 450052, China
}

mammals and humans around the world [1]. Trichinella spiralis infection in humans is mainly resulting from ingesting raw or semi-raw meat or meat products infected with the encapsulated muscle larvae (ML) of this nematode. In the Chinese mainland, 14 trichinellosis outbreaks due to infected pork from domestic pigs and wild boar were documented during 20042009 [2]. Swine pork is the major infectious source of human Trichinella infection in developing countries 
and areas [3-5]. Infections with Trichinella spp. are not merely a public health concern but also a severe hazard to animal food safety $[6,7]$. It is difficult to eradicate Trichinella spp. infection in animals as preventive antiTrichinella vaccines are not currently available. [8, 9]. Screening and identification of Trichinella spp. invasion-related proteins is recommended to help identify novel candidate targets for a vaccine against Trichinella infection [10].

After being eaten, $T$. spiralis ML encapsulate in the skeletal muscles and are released from their capsules in the stomach, where they develop into intestinal infective L1 larvae (IIL1) within the intestines. The IIL1 larvae intrude into enteral epithelia and continue to grow into adult worms (AW) by molting four times [11, 12]. Female adults give birth to newborn larvae (NBL), which pass into the bloodstream, penetrate into the skeletal muscles and encapsulate to accomplish the life-cycle [13]. The intestinal epithelial invasion by IIL1 larvae is the first infection, but the invasion mechanism is not clear. As intestinal epithelia are the preferential natural barrier against larval invasion, and the major site for host-T. spiralis interaction [14, 15], identification of IIL1 invasive proteins will be valuable to understand invasion mechanisms of the parasite and develop vaccines against $T$. spiralis intestinal invasive worms $[16,17]$.

Cathepsin B is one member of the cysteine protease family, which plays an important function in worm invading, migrating, molting and immune escape [18, 19]. Cysteine proteases have been identified in excretion/ secretion (ES) products or somatic proteins of T. spiralis ML and AW [20, 21]. When T. spiralis IIL1 larvae were inoculated onto an enteral epithelium cell monolayer, the IIL1 larvae penetrated the monolayer and expressed additional cysteine proteases which were found to be highly expressed at the IIL1 stage [22]. It might participate in IIL1 intrusion of the enteral epithelium during Trichinella infection [23-25].

In the present study, a novel cathepsin B gene of T. spiralis (TsCB, GenBank: XP_003379650.1) was obtained from the $T$. spiralis draft genome [26], cloned and expressed. The TsCB were characterized and the protective immunity triggered by $\mathrm{rTs} C B$ immunization were investigated in a mouse model.

\section{Methods}

\section{Worm maintenance and experimental animals}

Trichinella spiralis (ISS534) isolated from a domestic pig in central China was maintained in mice by serial passage in our laboratory [27]. Six-week-old female BALB/c mice were provided by the animal centre at Zhengzhou University.

\section{Worm collection and antigen preparation}

The ML were recovered by artificially digesting $T$. spiralis-infected mouse muscles at 35 days post-infection (dpi) $[28,29]$. The IIL1 were isolated from mouse intestine at $6 \mathrm{hpi}$ [30], and the AW were collected from mouse intestine on days 3 and 6 after infection [31]. After washes with sterile PBS, the day $6 \mathrm{AW}$ were cultured in RPMI-1640 medium (Gibco, Auckland, New Zealand) containing 10\% fetal bovine serum (50 female worms $/ \mathrm{ml}$ ), and the newborn larvae (NBL) were recovered $24 \mathrm{~h}$ following culture [32]. The soluble proteins of ML, IIL1, AW and NBL, and the ML ES proteins were prepared as previously reported [33, 34].

\section{Bioinformatics analysis of TsCB}

The complete cDNA sequence of the TsCB gene was acquired from GenBank (GenBank: XP_003379650.1). The characteristics of $\mathrm{TsCB}$ gene sequences were analyzed on the Expasy website (http://web.expasy.org/ protparam) as previously reported [35, 36]. PyMOL and CN3D software was used to predict the tertiary structure and functional sites of TsCB protein [37]. The cathepsin B sequences from Trichinella spp. and other organisms were retrieved from the GenBank database as follows: T. nativa (KRZ52829.1); T. murrelli (KRX41017.1); Trichinella sp. T6 (KRX78271.1); Trichinella sp. T8 (KRZ85246.1); T. britovi (KRY52058.1); T. nelsoni (KRX21942.1); T. pseudospiralis (KRY81987.1); Trichuris suis (KFD57259.1); Trichuris trichiura (CDW59512.1); Necator americanus (CAB53367.1); Haemonchus contortus (AAC05262.1); Ascaris suum (AAB40605.1); Clonorchis sinensis (ABM47070.1); Schistosoma mansoni (CAC85211.2); S. japonicum (CAA50305.1); Hymenolepis microstoma (CDS27962.1); Homo sapiens (NP_001899.1); and Mus musculus (EDL36070.1). The multiple alignment of the Ts CB sequences with the cathepsin $\mathrm{B}(\mathrm{CB})$ homologues of other organisms was conducted using Clustal X [38]. A phylogenetic tree of these CB sequences was generated using the maximum parsimony (MP) method as described by Sun et al. [39].

\section{RT-PCR quantification of TsCB transcript levels}

Total RNA was isolated with Trizol reagent (Invitrogen, Carlsbad, CA, USA) from worms of the different lifecycle stages (ML, IIL1, 3 days AW and NBL). TsCB transcript level at each stage was quantified by RT-PCR as reported [40]. Trichinella spiralis glyceraldehyde-3-phosphate dehydrogenase (GAPDH, GenBank: AF452239) was amplified as a housekeeping gene [41]. PBS was utilized as a negative control in all PCR amplification. 


\section{Cloning and expression of $\mathrm{rTs} C \mathrm{CB}$}

Total RNA from the ML was extracted using Trizol (Invitrogen). The complete TsCB sequences were amplified by PCR with specific primers incorporating the restriction enzyme sites $B a m H I$ and PstI (restriction sites underlined: 5'-GCG GAT CCA TTC CTT TTG GTT CCA GA-3'; 5'-AGC TGC AGT CAC GTT GGC TTC TTG TAC-3'). The PCR product was cloned into the $\mathrm{pQE}-80 \mathrm{~L}$ (Novagen, La Jolla, CA, USA), then the recombinant plasmid $\mathrm{pQE}-80 \mathrm{~L} / \mathrm{TsCB}$ was transformed into Escherichia coli BL21 (DE3) (Novagen). Expression of rTsCB was induced by $1 \mathrm{mM}$ IPTG at $37{ }^{\circ} \mathrm{C}$ for $6 \mathrm{~h}$ [17] and subsequently purified using Ni-NTA-Sefinose resin (Sangon Biotech Co., Shanghai, China) [42, 43]. The rTsCB concentration was assayed and analyzed by SDSPAGE at $120 \mathrm{~V}$ for $1.5 \mathrm{~h} \mathrm{[10].}$

\section{Immunization of mice and analysis of antibody responses to $\mathrm{rTs} C \mathrm{~B}$}

Sixty mice were divided into three groups of equal size (20 mice/group). Each mouse was subcutaneously vaccinated with $20 \mu \mathrm{g} \mathrm{rTsCB}$ emulsified with ISA 201 adjuvant (Seppic, Paris, France). Vaccination was repeated three times at 2-week intervals using the same dose of $\mathrm{rTs} C \mathrm{CB}$ and ISA 201. Control groups received only ISA 201 or PBS using the same vaccination procedure [44]. Individual serum samples were collected before vaccination and on weeks 2, 4, 6 and 8 after vaccination [45].

Specific antibody responses to rTsCB (total IgG, IgG1 as well IgG2a) in immunized mice were measured by ELISA two weeks after each vaccination $[37,46]$. The IgE response was also assayed by indirect ELISA using $\mathrm{rTs} C \mathrm{~B}$ as the coating antigen. The ELISA plate was coated using $2 \mu \mathrm{g} / \mathrm{ml} \mathrm{rTsCB}$ at $4{ }^{\circ} \mathrm{C}$ overnight. After washing, the plate was blocked using $5 \%$ skimmed milk in PBST, then probed with mouse immune sera $(1: 100)$ at $37^{\circ} \mathrm{C}$ for $1 \mathrm{~h}$. Goat anti-mouse IgG (IgG1 and IgG2a)-HRP conjugates (1:5000; Sigma-Aldrich, St. Louis, MO, USA) or Goat anti-mouse IgE-HRP conjugate (1:2500; Southern Biotech, Tuscaloosa, AL, USA) were added and incubated for $1 \mathrm{~h}$ at $37^{\circ} \mathrm{C}$. Detection was performed by adding the substrate OPD (Sigma-Aldrich, St. Louis, MO, USA) with $30 \% \mathrm{H}_{2} \mathrm{O}_{2}$ for $20 \mathrm{~min}$ and terminated using $2 \mathrm{M} \mathrm{H}_{2} \mathrm{SO}_{4}$ [47]. The absorbance at $492 \mathrm{~nm}$ was measured using a microplate reader (Tecan, Schweiz, AG, Switzerland) [48, 49].

\section{Western blot analysis}

Samples contained various proteins: somatic proteins of ML, IIL1, AW and NBL, ML ES antigens, and rTsCB (8 $\mu \mathrm{g}$ protein/lane). The protein was separated using SDSPAGE with a $12 \%$ resolving gel $[33,50]$; the gel was then transferred to a nitrocellulose membrane (Merck Millipore, Billerica, MA, USA) [48]. The membrane was cut into strips, blocked using 5\% skimmed milk in TBST. After three washes in TBST, the strips were probed using 1:100 dilution of three different mouse sera (anti-rTsCB serum, mouse infection serum, and pre-immune normal mouse serum) for $1 \mathrm{~h}$ at $37{ }^{\circ} \mathrm{C}$. The blots were washed with TBST then incubated with anti-mouse IgG HRPconjugate $\left(1: 10,000\right.$; Southern Biotech) at $37^{\circ} \mathrm{C}$ for $1 \mathrm{~h}$. Detection was achieved using 3, 3'-diaminobenzidine tetrahydrochloride (DAB; Sigma-Aldrich) [15, 51].

\section{Indirect immunofluorescence assay (IIFA)}

Expression and tissue localization of natural TsCB in the nematode were investigated using IIFA with anti-rTsCB serum $[42,52]$. Paraffin sections ( $3 \mu \mathrm{m}$ thick) of the different worm life-cycle stages were used to examine TsCB expression and tissue localization in T. spiralis. Each section was blocked with 5\% normal goat serum (Sangon, Shanghai, China), and probed at $37^{\circ} \mathrm{C}$ for $1 \mathrm{~h}$ with three different sera (1:10; anti-rTsCB serum, mouse infection serum and pre-immune serum). Following three washes with PBS, the sections were stained at $37^{\circ} \mathrm{C}$ for $1 \mathrm{~h}$ using FITC-conjugated anti-mouse IgG (1:100; Santa Cruz, USA). Sections were washed as previously reported and examined using fluorescent microscopy (Olympus, Tokyo, Japan) $[49,53]$.

\section{Challenge experiment}

To investigate the immune protection offered by vaccination with $\mathrm{rTs} C \mathrm{~B}$, all mice were infected orally with 300 T. spiralis ML at two weeks after the final boost. Intestinal adults were collected from 10 mice at 6 dpi [54], and muscle larvae at 35 dpi were obtained by artificially digesting the carcasses of the remaining 10 mice [55]. Immune protection was ascertained as worm reduction of enteral adults and larvae per gram (LPG) of skeletal muscles of immunized groups compared to those of the PBS control group $[8,56,57]$.

\section{Statistical analysis}

All statistical analysis was conducted using SPSS for Windows, version 22.0 (SPSS Inc., Chicago, IL, USA). The values are presented as the mean \pm standard deviation (SD). Difference among various groups was analyzed using a Student's t-test or one-way ANOVA. $P<0.05$ was regarded as a level for statistical significance.

\section{Results \\ Bioinformatics analysis of TsCB sequence}

Bioinformatics analyses revealed that the full-length TsCB sequence was $1071 \mathrm{bp}$, encoding a protein of 356 amino acids, with $40.23 \mathrm{kDa}$ and 7.86 isoelectric point 
(pI). Analyses with Signal P 4.1 and TMHMM Server indicated that the signal peptide was located at 1-29 aa, TsCB had $7 \alpha$-helixes and $13 \beta$-strands, and a transmembrane domain was located outside the cell membrane. Subcellular localization of TsCB was present in mitochondria (2\%), periplasm (94.9\%) and cytoplasm (6.7\%), respectively. The homology comparison of TsCB sequences with those of other Trichinella species or genotypes are shown in Fig. 1. TsCB amino acid sequence had $98 \%$ identity with cathepsin B of T. nativa, T. murrelli, T6, T8, T. britovi and T. nelsoni, and 95\% identity with T. pseudospiralis.

Phylogenetic analysis of TsCB with cathepsin B from other species is shown in Fig. 2a. The phylogenetic tree generated using the MP method verified a monophyletic group of the above-mentioned 7 species/gene types

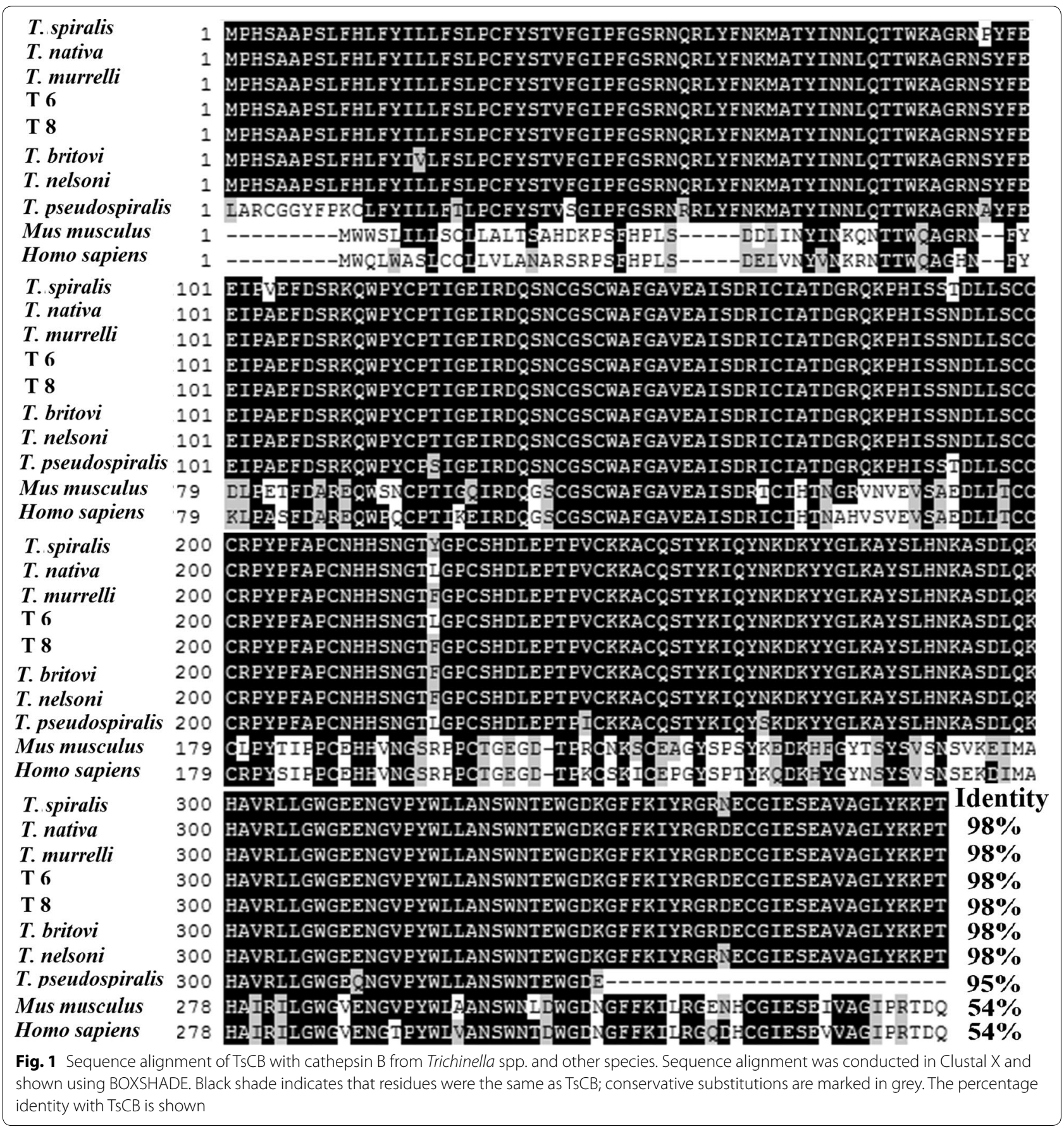



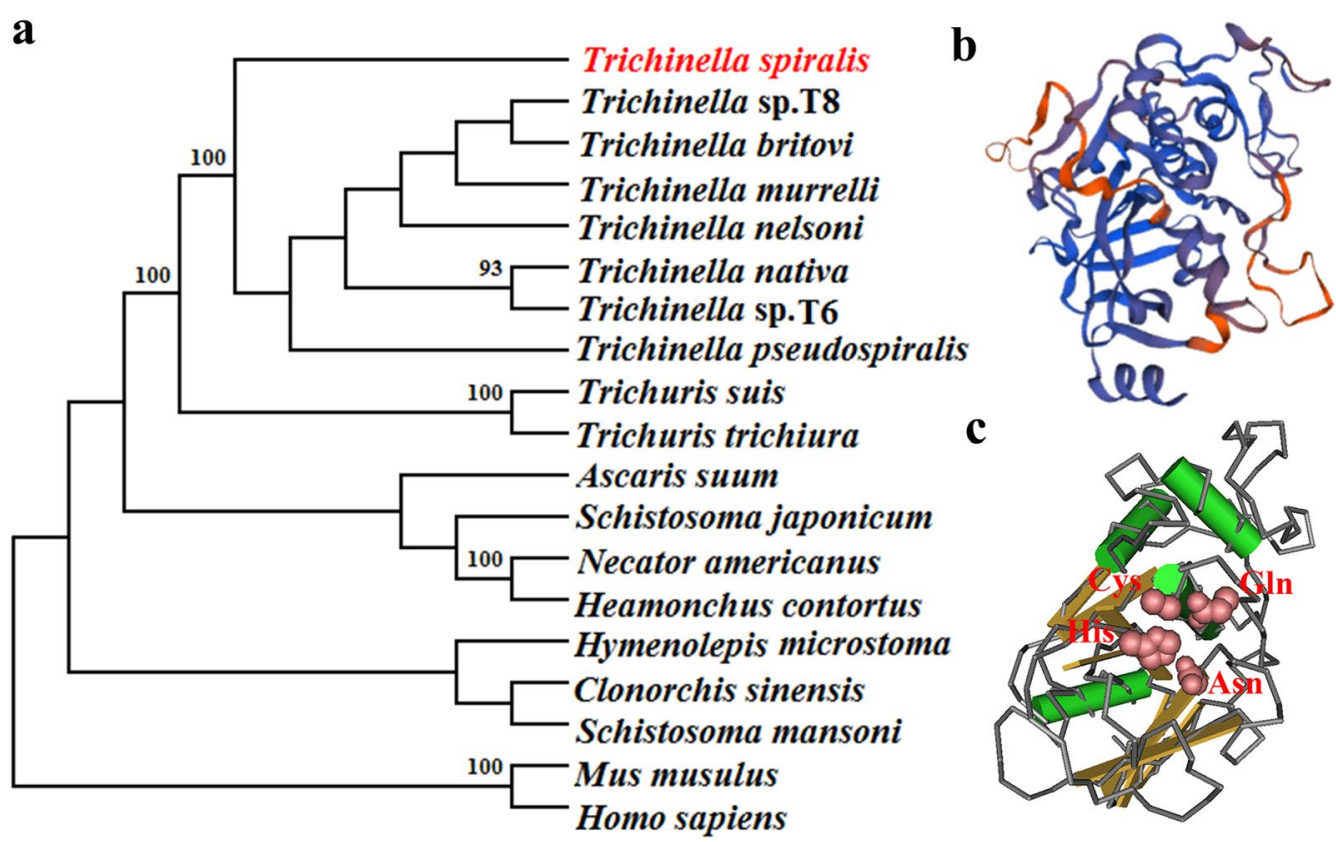

Fig. 2 Phylogenetic trees of cathepsin B of 19 organisms estimated with the MP method (a) and the predicted 3-dimensional structure of T. spiralis cathepsin B (b, c). b The predicted 3-dimensional structure of TsCB contains 7 a-helixes (red) and $13 \beta$-strand (blue). c Functional domain carrying catalytic reactive sites consisted of Gln124, Cys155, Asn305, and Gly328 residues, formed a functional domain. The TsCB active sites are highlighted in red

within the genus Trichinella. Trichinella spiralis has a close evolutionary relationship with encapsulated and non-encapsulated Trichinella species, and is more closely related to nematode cathepsin $\mathrm{B}$ than that from other species.

The SMART analysis results revealed that there was a functional domain (between positions 102-351 aa) of peptidase_C1A. In a 3-dimensional model, TsCB had the catalytic active sites, which were composed of Gln124, Cys130, His300 and Asn320 residues, forming a pocketshaped functional domain carrying substrate binding sites (Fig. 2c).

\section{RT-PCR analysis of TsCB transcription}

Transcription of the TsCB mRNA was assayed by RTPCR for the four parasite life-cycle stages and the GAPDH gene was used as an internal control. A TsCB transcript (984 bp) was detected in muscle larvae, IIL1, adults and NBL. Primers for GAPDH also generated the expected size (570 bp) at all stages (Fig. 3).

\section{Western blot identification of $\mathrm{rTs} C \mathrm{~B}$}

The results of SDS-PAGE revealed that the BL21 bacteria carrying $\mathrm{PQE}-80 \mathrm{~L} / \mathrm{Ts} \mathrm{CB}$ expressed a $39.7 \mathrm{kDa}$ fusion protein. After purification, the $\mathrm{rTs} C \mathrm{~B}$ protein exhibited a clear individual band (Fig. 4a). The molecular weight

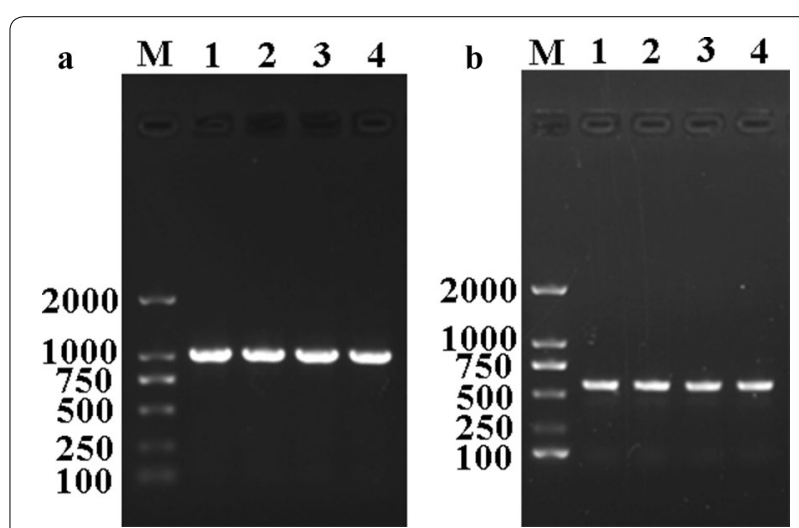

Fig. 3 RT-PCR analysis of the transcription of TsCB (a) and GAPDH (b) for the life-cycle stages of T. spiralis studied. Lane M: DL2000 DNA marker; Lane 1: muscle larvae; Lane 2: IIL1 larvae; Lane 3: 3d adults; Lane 4: NBL

(MW, $39.7 \mathrm{kDa}$ ) of rTsCB was identical to its predicted size.

Western blotting results exhibited that $\mathrm{rTsCB}$ was recognized by anti-rTsCB antibodies, but not by infection serum and normal mouse serum (Fig. 4b). Using antirTsCB antibodies, native TsCB was detected in soluble proteins of muscle larvae, IIL1, 3-days adults and NBL, but not in muscle larva ES proteins (Fig. 4b, c), indicating 


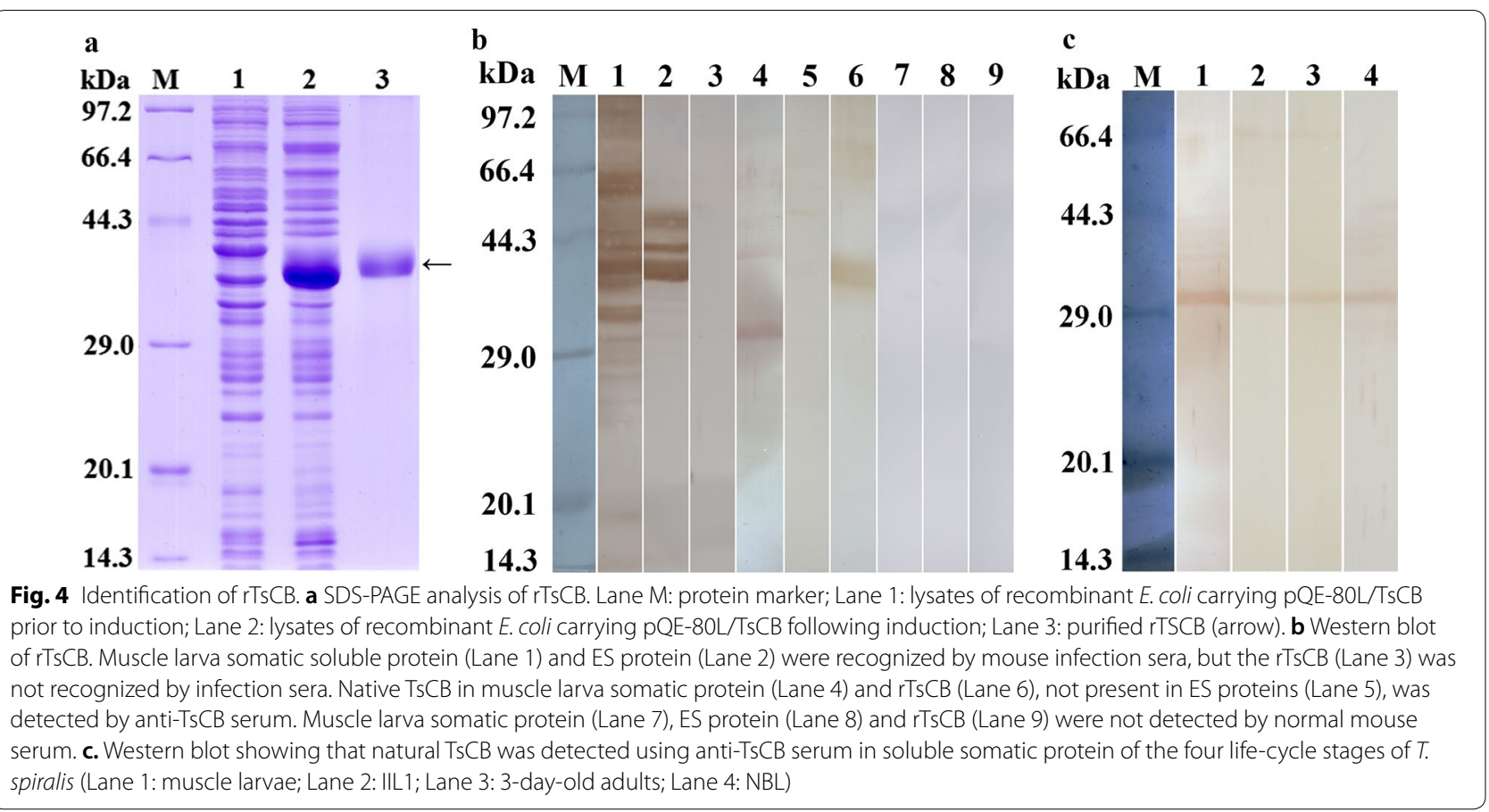

that the $\mathrm{TsCB}$ is one somatic protein of this nematode, but not a secretory protein from muscle larvae.

\section{Expression and localization of TsCB in the nematode life-cycle stages}

The IIFA result revealed that the fluorescence staining was detected in the four life-cycle stages (ML, IL1, 3-days female adult and embryos) by anti-rTsCB antibodies. The fluorescence was distributed in the cuticle and stichosome of the nematode and in the embryos within female uterus (Fig. 5). Fluorescence staining with pre-immune serum was not observed.

\section{Specific antibody response}

To determine specific antibody responses to rTsCB, rTsCB-specific IgG, IgG1 as well IgG2a, and IgE in serum samples of vaccinated mice, responses were measured using an rTsCB-ELISA. The anti-rTsCB IgG titer was 1:10,000 after the third immunization (Fig. 6), indicating that the $\mathrm{rTs} C \mathrm{~B}$ was a strong immunogenic. The antirTsCB IgG level in vaccinated mice was prominently raised following the second immunization, whereas no mice vaccinated with ISA 201 or PBS exhibited any antirTsCB antibody responses (Fig. 7a). The IgG1 levels at 4, 6 and 8 weeks post-immunization were prominently higher than IgG2a (week 4: $t_{(18)}=4.350, P<0.0001$; week 6: $t_{(18)}=4.247, P<0.0001$; week 8: $\left.t_{(18)}=2.902, P=0.009\right)$ (Fig. 7b, c), demonstrating that immunization with rTsCB elicited a Th2-predominant Th1/Th2 mixed immune response. Moreover, anti-rTsCB IgE was also determined, and the results showed that the specific IgE level was significantly elevated in mice immunized with $\mathrm{rTsCB}$ in comparison to the control groups $\left(F_{(4,45)}=568.102\right.$, $P<0.0001$ ) (Fig. 7d), suggesting that specific IgE antibodies might play a crucial action in TsCB-induced rapid worm expulsion from the gut.

\section{Immune protection of rTsCB immunization against larval challenge}

Compared with PBS control mice, the mice immunized with $\mathrm{rTsCB}$ exhibited a $52.81 \%$ reduction of intestinal adults at 6 dpi (Fig. 8a) and a 50.90\% reduction of muscle larvae at $35 \mathrm{dpi}$ (Fig. 8b) after oral challenge with 300 T. spiralis infective larvae. The in vitro NBL production for $72 \mathrm{~h}$ of adult females from rTsCB-immunized mice was significantly inferior to that of control mice (Fig. 8c) $\left(F_{(2,27)}=11.153, P<0.0001\right)$. This result showed that the immunization with $\mathrm{rTs} C \mathrm{~B}$ elicited an immune protection against the $T$. spiralis challenge infection.

The length of adult females collected from rTsCB-immunized mice at $6 \mathrm{dpi}$ was evidently smaller than that from ISA 201 adjuvant or PBS control mice (Figs. 9, 10) $\left(F_{(2}\right.$, $\left.{ }_{27}=19.390, P<0.0001\right)$; but the length of adult males did not show statistically significant difference among the three groups $\left(F_{(2,27)}=1.849, P=0.177\right)$. Moreover, the length of NBL produced by the adult females in immunized mice was clearly shorter than that from the PBS group $\left(F_{(2,27)}=24.788\right.$, $P<0.0001)$. The muscle larva length from immunized mice 

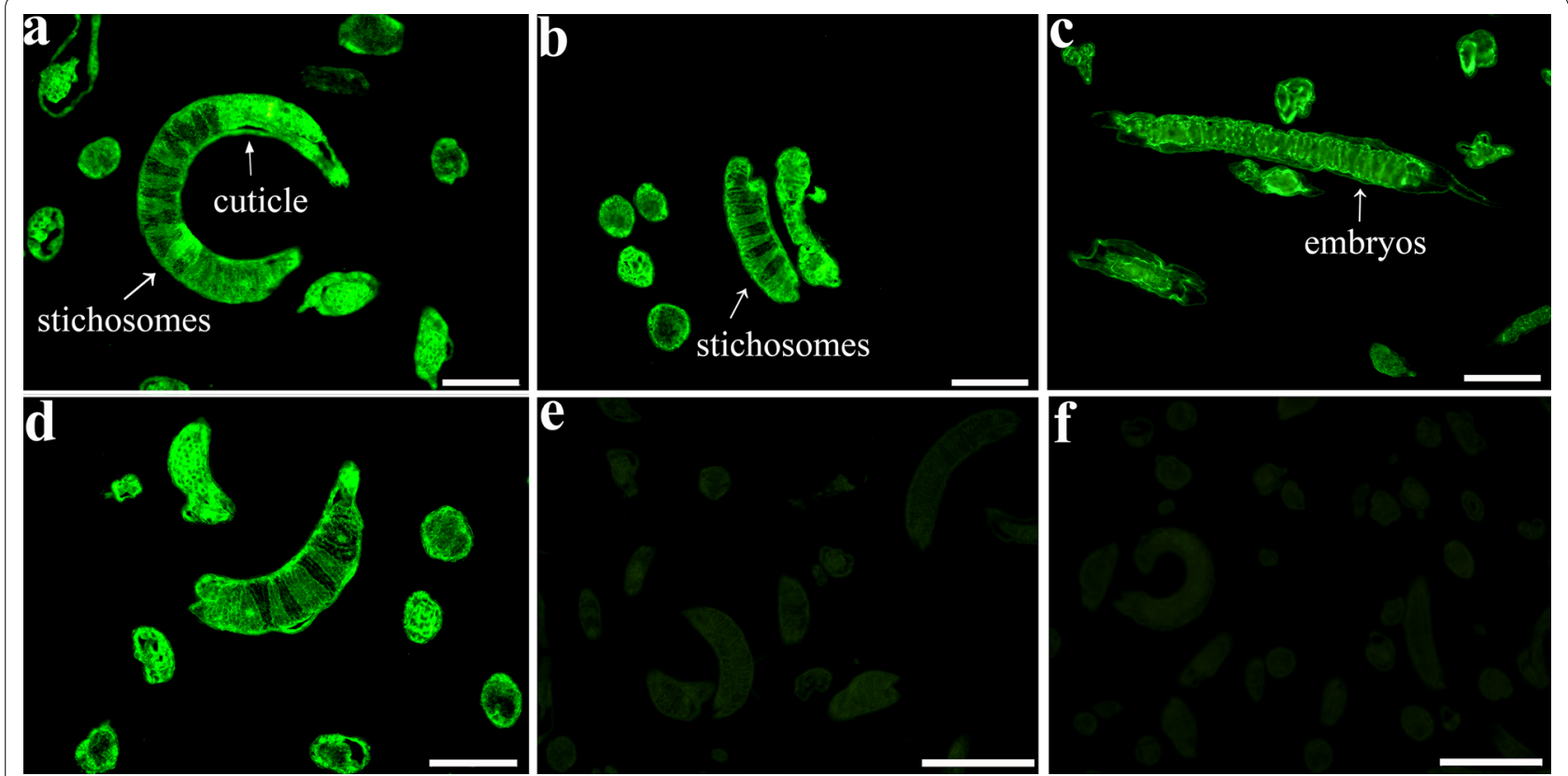

Fig. 5 Location of TsCB of different life-cycle stages of T. spiralis by IIFA using anti-rTsCB antibody. Green fluorescence staining was detected in the cuticle and stichosome of the muscle larvae (a) and IIL1 larvae (b), 3-day-old females and embryos (c). Muscle larva incubated by infection sera was utilized as a positive control (d). Muscle larva incubated with pre-immune sera (e) and PBS (f) were used as negative controls. Scale-bars: $50 \mu m$

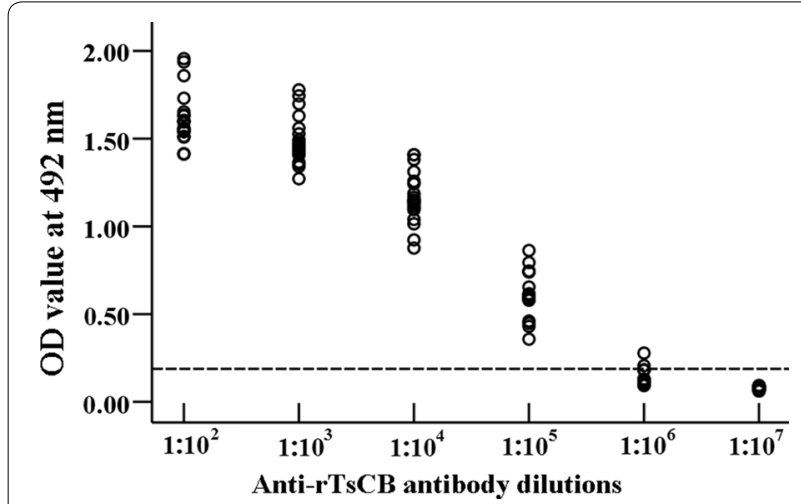

Fig. 6 Serum anti-rTsCB lgG titers determined by rTsCB-ELISA. The $\mathrm{OD}$ values are shown as the mean \pm SD of anti-rTsCB IgG levels of 20 immunized mice

was also significantly shorter than that of control mice $\left(F_{(2,}\right.$ $\left.{ }_{87)}=68.216, P<0.0001\right)$. These results indicate that the immune response elicited by immunization with $\mathrm{rTs} C \mathrm{CB}$ also hampered the parasite growth and development, reduces the female reproductive capacity, as a result, alleviate the muscle larva burdens in immunized mice.

\section{Discussion}

In the present study, the complete cDNA sequence of the $\mathrm{TsCB}$ gene was cloned, expressed, and its biological characteristics were investigated. The full-length $\mathrm{Ts} \mathrm{CB}$ sequence was $1071 \mathrm{bp}$ encoding a $40.23 \mathrm{kDa}$ protein. The amino acid sequences of the TsCB gene had 98\% identity with the cathepsin B of six encapsulated species/gene types of the genus Trichinella (T. nativa, T. murrelli, T6, T8, T. britovi and T. nelsoni). Our results demonstrated that $\mathrm{rTsCB}$ were expressed in $E$. coli, with a molecular weight of approximately $40.23 \mathrm{kDa}$ identical to the expected size. After being purified, rTsCB had strong immunogenic properties. Western blot results showed that native TsCB in somatic proteins of muscle larvae, IIL1, 3-day-old adults and NBL were identified by anti-rTsCB antibodies, but not in muscle larval ES protein, indicating that the $\mathrm{Ts} C \mathrm{~B}$ is one somatic protein of this nematode, but not a secretory protein of muscle larvae. In the present study, TsCB transcription and expression were also investigated using RT-PCR and IIFA. RT-PCR results indicated that the TsCB gene was transcribed in the four T. spiralis life-cycle stages (muscle larva, IIL, adult and NBL). TsCB expression was detected by IIFA for all $T$. spiralis life-cycle stages, immunofluorescence staining was located in the cuticle, stichosome and intrauterine embryos of this parasitic nematode, suggesting that TsCB as a surface protein might play a role during larval intrusion of the host's small intestinal epithelium [30, 58]. Surface proteins of T. spiralis intestinal stage worms are exposed directly to the host's enteral milieu and local mucosal immune system, they are the important antigenic molecules, and can play a key role 

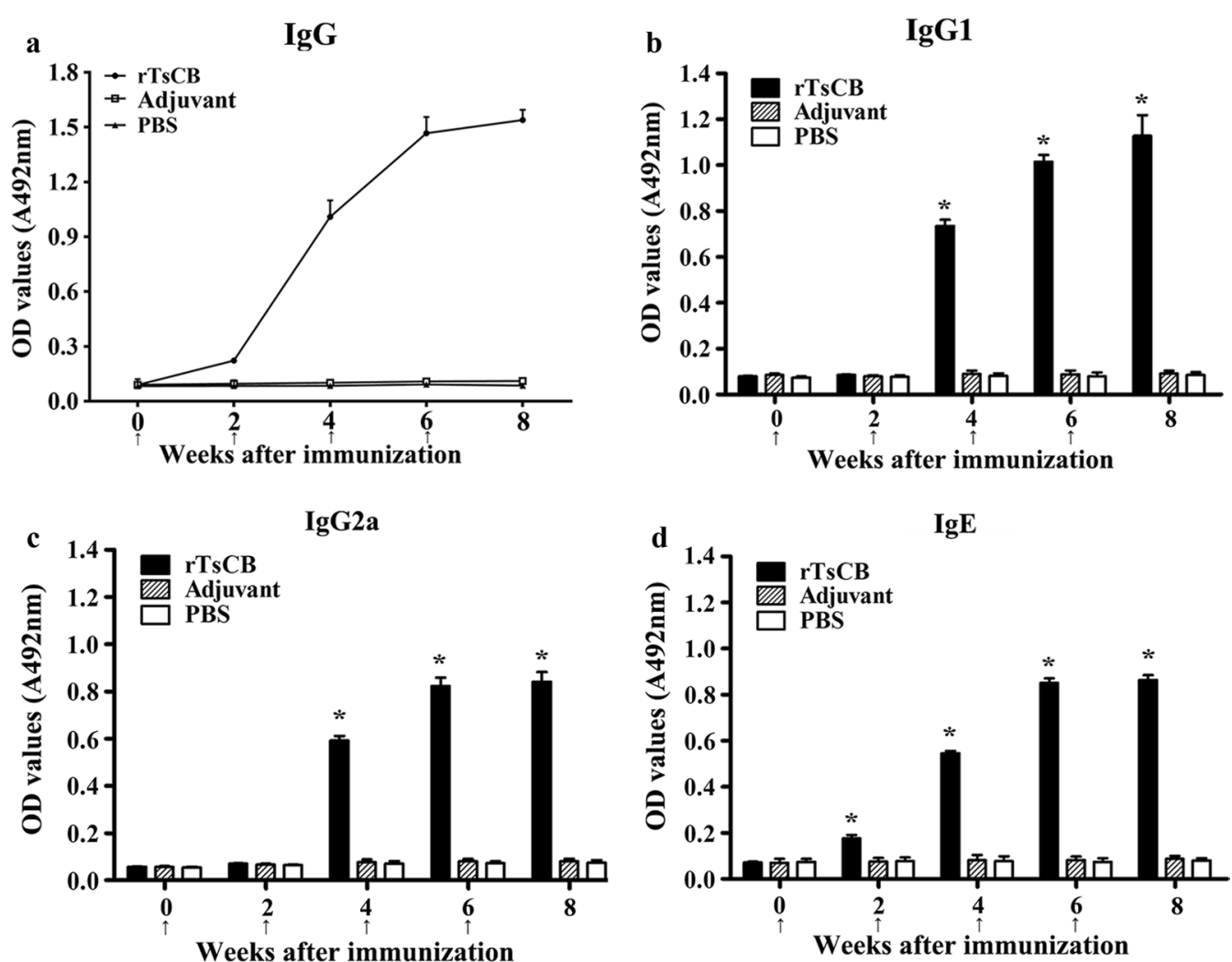

Fig. 7 Specific antibody response in mice immunized with $r T s C B$. a Specific total lgG in mice immunized with rTsCB or control mice (adjuvant and PBS) at different time intervals following vaccination. Specific lgG1 (b) and lgG2a (c) subclass responses against rTsCB at different time points following vaccination. $\mathbf{d}$ Specific IgE level in vaccinated mice. The OD values are shown as the mean \pm SD of antibody levels $(n=10)$. Vaccination time point is indicated with an arrow. ${ }^{*} P<0.001$ compared with adjuvant or PBS group
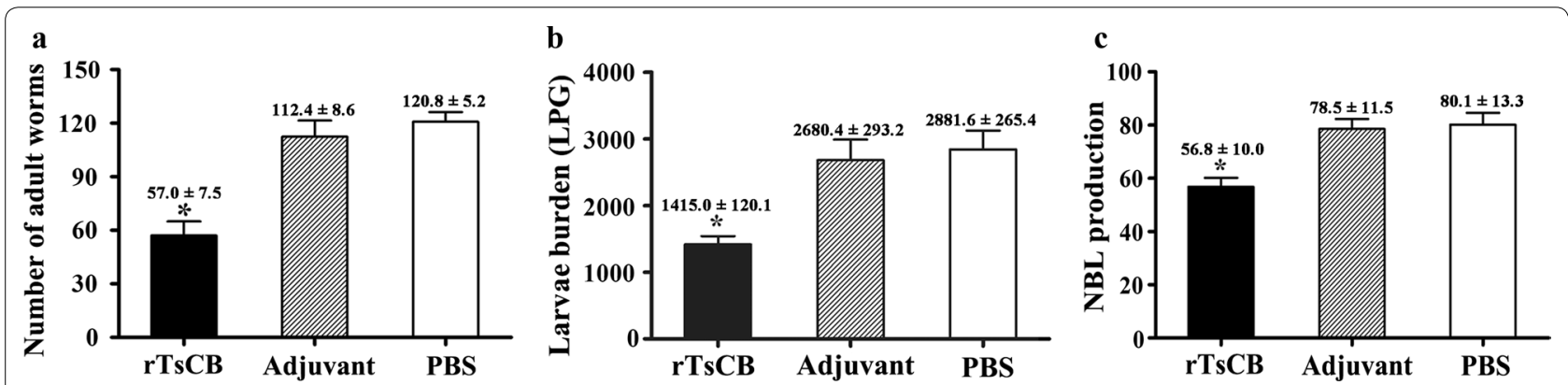

Fig. 8 Protective efficacy of immunization with rTsCB against a challenge with 300 muscle larvae. a Number of adults in the intestine at 6 days post-infection. $\mathbf{b}$ Muscle larvae burden (larvae per gram of muscles, LPG) at 35 days post-infection. Worm burden is represented as the mean \pm SD of 10 animals/group. c NBL production of each female adult from immunization and control mice. ${ }^{*} P<0.01$ compared with adjuvant or PBS group

in larval intrusion and development [23, 24]. Previous studies have shown that recombinant $T$. spiralis surface proteins (nudix hydrolase, serine protease, cysteine protease, etc.) participate in larva penetration of intestinal epithelia $[15,19,41]$. Our previous study demonstrated that when the in vitro larva invasion experiment was performed, rTsCB promoted larva invasion of enterocytes, whereas rTsCB-specific antibodies suppressed larva invasion, this promotion or suppression was dose-dependent of rTsCB or rTsCB-specific antibodies. Silencing TsCB using RNAi significantly impeded the larva invasion (Han et al., unpublished data). The present study suggests that TsCB plays a major part on intestinal mucosal intrusion by this intracellular parasitic nematode. 


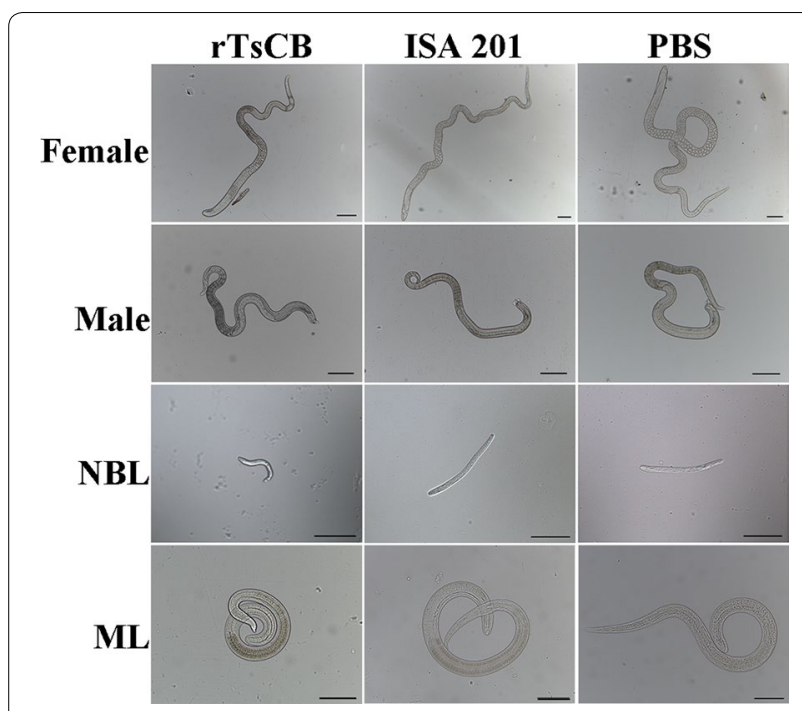

Fig. 9 Morphology of various T. spiralis stages from mice immunized with rTsCB at 6 and 35 days following challenge with infective larvae. Scale bars: $100 \mu \mathrm{m}$

Vaccination of mice with $\mathrm{rTs} C \mathrm{~B}$ elicited a specific Th2predominant (higher level of IgG1) antibody response to $\mathrm{rTsCB}$. The intestinal and muscle worm reduction observed in the present study is parallel with that of mice vaccinated with recombinant $T$. spiralis serine proteases [8], nudix hydrolase $[45,59]$ and glutathione $\mathrm{S}$-transferase [42]. The immune protection induced by vaccination with $\mathrm{rTs} C \mathrm{~B}$ may be related to the generation of high levels of serum anti-TsCB IgG antibodies, which neutralized the capacity of cathepsin $\mathrm{B}$ to degrade enteral epithelium and other tissues of hosts [20]. Anti-Trichinella IgG may also bind to the epicuticle of enteral IIL1 larvae and generate an antigen-antibody complex in the larva anterior end, which may physically prevent parasite contact from intestinal epithelium cells, thus protect the intestinal epithelium from larval invasion [56, 60]. Antibodies against a cathepsin B-like protease (Ac-cathB-1) of Angiostrongylus cantonensis inhibited the L3 larva invasion of the intestines in rats [61]. In addition, previous studies indicated that anti-Trichinella IgG destroyed T. spiralis NBL and ML through an ADCC pattern [53, $62,63]$.

In the present study, the level of anti-TsCB IgE serum in vaccinated mice was also determined. The results showed that vaccination with $\mathrm{rTs} C B$ elicited specific IgE, which plays a major role in the rapid expulsion of intestinal infective larvae and adult worms from the guts of vaccinated animals and in delaying larva invasion of intestinal epithelium after oral infection $[64,65]$. Specific IgE is transported from the blood and exerts an active role in enteral lumen. The IgE combines with the worm surface of T. spiralis and mediates mast cell degranulation to prevent invasion $[66,67]$. Moreover, IgE also plays an important action in destroying NBL by an antibodydependent cellular cytotoxicity (ADCC) mode [68]. Our results demonstrated that vaccination with $\mathrm{rTs} C \mathrm{CB}$
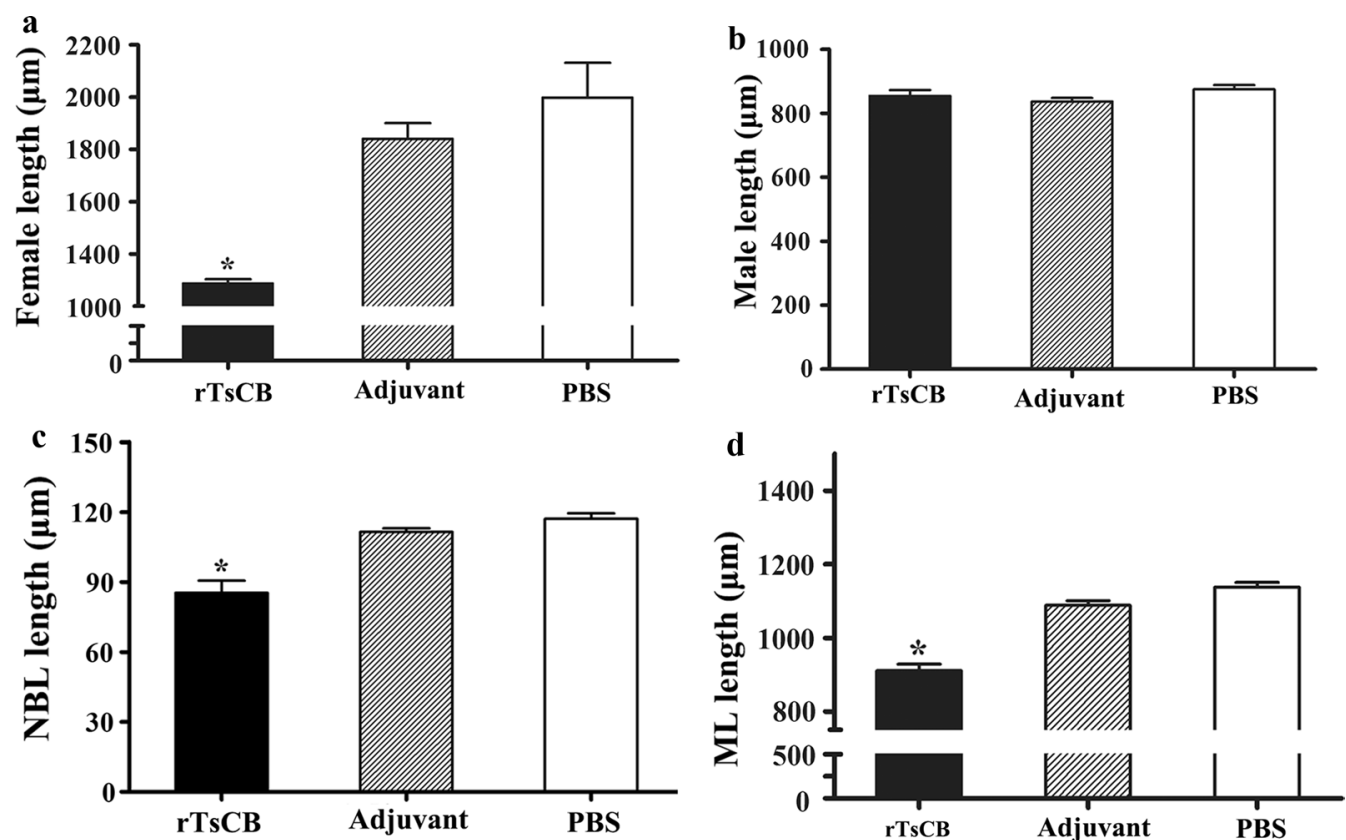

Fig. 10 Length of different life-cycle stages of T. spiralis from mice immunized with rTsCB at 6 and 35 days after challenge $(n=10)$. a Female adult worms. b Male adult worms. $\mathbf{c}$ Newborn larvae (NBL). d Muscle larvae (ML). ${ }^{*} P<0.01$ compared with adjuvant and PBS groups 
elicited a high level of TsCB-specific IgG and IgE antibodies, which resulted in a significant reduction of worm burdens in the intestine and skeletal muscles of rTsCBvaccinated mice. The results suggest that specific IgG and IgE antibodies are crucial for protective immunity against a T. spiralis challenge infection [69].

Additionally, our results also revealed that the length of female adults recovered from immunized mice and the female reproductive capacity (NBL production/female in vitro for 72 hours) was obviously lower than that of the ISA 201 adjuvant or PBS control mice. Length of NBL produced by females from immunized mice was significantly shorter than that of the ISA 201 and PBS groups. These results suggest that immune responses elicited by immunization with $\mathrm{rTs} C \mathrm{CB}$ also impeded intestinal worm growth, and declined the fecundity [56, 70]. A decline in female reproductive capacity might be related with females becoming shorter, since the uterus length has a correlation with female fecundity [71].

Trichinella spiralis is a multicellular parasite and its life-cycle is complicated. Different $T$. spiralis life-cycle stages have stage-specific antigens [72]. Vaccination with an individual Trichinella protein molecule only induced partial protective immunity against challenge. Therefore, oral polyvalent vaccines against diverse $T$. spiralis stages need to be developed [16, 44].

\section{Conclusions}

TsCB was expressed in diverse life-cycle stages of $T$. spiralis and primarily located in the cuticle and stichosome of this intracellular parasite. Vaccination of mice with $\mathrm{rTs} C \mathrm{~B}$ elicited highly specific IgG and IgE responses and partial immune protection, as demonstrated by a significant worm burden reduction in the intestines and muscles of vaccinated mice after oral challenge with $T$. spiralis infective larvae. The humoral immune responses generated by immunization with $\mathrm{rTsCB}$ also impeded intestinal worm growth and declined its fecundity. The results show that TsCB might be considered as a novel potential molecular target to develop vaccines against $T$. spiralis infection.

\begin{abstract}
Abbreviations
ADCC: antibody-dependent cellular cytotoxicity; AW: adult worms; DAB: 3,3'-diaminobenzidine tetrahydrochloride; dpi: days post-infection; ES: excretion/secretion; GAPDH: glyceraldehyde-3-phosphate dehydrogenase; IIFA: indirect immunofluorescence assay; IIL 1: intestinal infective L1 larvae; ML: muscle larvae; MP: maximum parsimony; NBL: newborn larvae; rTsCB: recombinant TsCB; TsCB: Trichinella spiralis cathepsin B.
\end{abstract}

\section{Acknowledgements}

Not applicable.

\section{Authors' contributions}

JC, PJ and ZQW designed this study. YH, XY, FL, YYS, SWY, JJL, PJ and XZ performed the experiments. $\mathrm{YH}, J \mathrm{C}$ and $\mathrm{ZQW}$ drafted and revised the manuscript. All authors read and approved the final manuscript.
Funding

This study was supported by National Natural Science Foundation of China (U1704284).

\section{Availability of data and materials}

The data supporting the conclusions of this article are included within the article.

\section{Ethics approval and consent to participate}

This research was carried out based on the National Guidelines for Experimental Animal Welfare (Minister of Science and Technology, the People's Republic of China, 2006). All procedures of animal experiment were authorized by the Institutional Life Science Ethics Committee, Zhengzhou University (No. SCXK 2017-0001)

\section{Consent for publication}

Not applicable.

\section{Competing interests}

The authors declare that they have no competing interests.

Received: 14 June 2019 Accepted: 2 December 2019

Published online: 11 December 2019

References

1. Pozio E. World distribution of Trichinella spp. infections in animals and humans. Vet Parasitol. 2007;149:3-21.

2. Cui J, Wang ZQ, Xu BL. The epidemiology of human trichinellosis in China during 2004-2009. Acta Trop. 2011;118:1-5.

3. Cui J, Jiang P, Liu LN, Wang ZQ. Survey of Trichinella infections in domestic pigs from northern and eastern Henan. China. Vet Parasitol. 2013;194:133-5.

4. Jiang $P$, Zhang $X$, Wang LA, Han LH, Yang M, Duan JY, et al. Survey of Trichinella infection from domestic pigs in the historical endemic areas of Henan Province, central China. Parasitol Res. 2016;115:4707-9.

5. Rostami A, Gamble HR, Dupouy-Camet J, Khazan H, Bruschi F. Meat sources of infection for outbreaks of human trichinellosis. Food Microbiol. 2017;64:65-71.

6. Cui J, Wang ZQ. An epidemiological overview of swine trichinellosis in China. Vet J. 2011;190:323-8.

7. Bai X, Hu X, Liu X, Tang B, Liu M. Current research of trichinellosis in China. Front Microbiol. 2017:8:1472

8. Li JF, Guo KX, Qi X, Lei JJ, Han Y, Yan SW, et al. Protective immunity against Trichinella spiralis in mice elicited by oral vaccination with attenuated Salmonella-delivered TsSP1.2 DNA. Vet Res. 2018;49:87.

9. Zhang N, Li W, Fu B. Vaccines against Trichinella spiralis: progress, challenges and future prospects. Transbound Emerg Dis. 2018;65:1447-58.

10. Wang ZQ, Wang L, Cui J. Proteomic analysis of Trichinella spiralis proteins in intestinal epithelial cells after culture with their larvae by shotgun LC-MS/MS approach. J Proteomics. 2012;75:2375-83.

11. Ren HJ, Cui J, Wang ZQ, Liu RD. Normal mouse intestinal epithelial cells as a model for the in vitro invasion of Trichinella spiralis infective larvae. PloS One. 2011;6:e27010.

12. Liu RD, Wang ZQ, Wang L, Long SR, Ren HJ, Cui J. Analysis of differentially expressed genes of Trichinella spiralis larvae activated by bile and cultured with intestinal epithelial cells using real-time PCR. Parasitol Res. 2013;112:4113-20.

13. Despommier DD. How does Trichinella spiralis make itself at home? Parasitol Today. 1998;14:318-23.

14. Liu RD, Jiang P, Wen H, Duan JY, Wang LA, Li JF, et al. Screening and characterization of early diagnostic antigens in excretory-secretory proteins from Trichinella spiralis intestinal infective larvae by immunoproteomics. Parasitol Res. 2016;115:615-22.

15. Sun GG, Ren HN, Liu RD, Song YY, Qi X, Hu CX, et al. Molecular characterization of a putative serine protease from Trichinella spiralis and its elicited immune protection. Vet Res. 2018;49:59.

16. Ortega-Pierres G, Vaquero-Vera A, Fonseca-Linan R, Bermudez-Cruz RM, Arguello-Garcia R. Induction of protection in murine experimental 
models against Trichinella spiralis: an up-to-date review. J Helminthol. 2015;89:526-39.

17. Xu J, Yang F, Yang DQ, Jiang P, Liu RD, Zhang X, et al. Molecular characterization of Trichinella spiralis galectin and its participation in larval invasion of host's intestinal epithelial cells. Vet Res. 2018;49:79.

18. Sajid M, McKerrow JH. Cysteine proteases of parasitic organisms. Mol Biochem Parasitol. 2002;120:1-21.

19. Song YY, Wang LA, Na Ren H, Qi X, Sun GG, Liu RD, et al. Cloning, expression and characterisation of a cysteine protease from Trichinella spiralis. Folia Parasitol (Praha). 2018;65:007

20. Todorova VK. Proteolytic enzymes secreted by larval stage of the parasitic nematode Trichinella spiralis. Folia Parasitol (Praha). 2000;47:141-5.

21. Yang J, Pan W, Sun X, Zhao X, Yuan G, Sun Q, et al. Immunoproteomic profile of Trichinella spiralis adult worm proteins recognized by early infection sera. Parasit Vectors. 2015;8:20.

22. Wang L, Wang ZQ, Cui J. Proteomic analysis of the changed proteins of Trichinella spiralis infective larvae after co-culture in vitro with intestinal epithelial cells. Vet Parasitol. 2013;194:160-3.

23. Bolas-Fernandez F, Bezara LD. TSL-1 antigens of Trichinella: an overview of their potential role in parasite invasion, survival and serodiagnosis of trichinellosis. Res Vet Sci. 2006;81:297-303.

24. Nagano I, Wu ZL, Takahashi Y. Functional genes and proteins of Trichinella spp. Parasitol Res. 2009;104:197-207.

25. Qu ZG, Ma XT, Li WH, Zhang NZ, Yue L, Cui JM, et al. Molecular characterization of a cathepsin F-like protease in Trichinella spiralis. Parasit Vectors. 2015;8:652.

26. Mitreva M, Jasmer DP, Zarlenga DS, Wang Z, Abubucker S, Martin J, et al. The draft genome of the parasitic nematode Trichinella spiralis. Nat Genet. 2011:43:228-35.

27. Wang ZQ, Li LZ, Jiang P, Liu LN, Cui J. Molecular identification and phylogenetic analysis of Trichinella isolates from different provinces in mainland China. Parasitol Res. 2012;110:753-7.

28. Li F, Cui J, Wang ZQ, Jiang P. Sensitivity and optimization of artificial digestion in the inspection of meat for Trichinella spiralis. Foodborne Pathog Dis. 2010;7:879-85.

29. Jiang P, Wang ZQ, Cui J, Zhang X. Comparison of artificial digestion and Baermann's methods for detection of Trichinella spiralis pre-encapsulated larvae in muscles with low-level infections. Foodborne Pathog Dis. 2012;9:27-31.

30. Liu RD, Cui J, Liu XL, Jiang P, Sun GG, Zhang X, et al. Comparative proteomic analysis of surface proteins of Trichinella spiralis muscle larvae and intestinal infective larvae. Acta Trop. 2015;150:79-86.

31. Sun GG, Wang ZQ, Liu CY, Jiang P, Liu RD, Wen H, et al. Early serodiagnosis of trichinellosis by ELISA using excretory-secretory antigens of Trichinella spiralis adult worms. Parasit Vectors. 2015;8:484

32. Wu ZL, Nagano I, Takahashi Y, Maekawa Y. Practical methods for collecting Trichinella parasites and their excretory-secretory products. Parasitol Int. 2016;65:591-5.

33. Wang L, Wang ZQ, Cui J. Protein changes in Trichinella spiralis muscle larvae in vitro induced by bovine bile. Vet Parasitol. 2013;194:164-7.

34. Yang W, Li LG, Liu RD, Sun GG, Liu CY, Zhang SB, et al. Molecular identification and characterization of Trichinella spiralis proteasome subunit beta type-7. Parasit Vectors. 2015:8:18.

35. Liu LN, Wang ZQ, Zhang X, Jiang P, Zhang ZF, Zhang GY, et al. Analysis of structure, function and epitopes of Spirometra erinaceieuropaei casein kinase I. Trop Biomed. 2015;32:167-75.

36. Zhang YL, Zhang HW, Zhang X, Liu LN, Liu RD, Xu BL, et al. Analysis of structures, functions, and epitopes of aminopeptidase from Trichinella spiralis. Trop Biomed. 2015;32:776-82.

37. Song YY, Zhang Y, Yang DQ, Ren HN, Sun GG, Jiang P, et al. The immune protection induced by a serine protease inhibitor from the foodborne parasite Trichinella spiralis. Front Microbiol. 2018;9:1544.

38. Larkin MA, Blackshields G, Brown NP, Chenna R, McGettigan PA, McWilliam H, et al. Clustal W and clustal X version 2.0. Bioinformatics. 2007:23:2947-8

39. Sun GG, Song YY, Jiang P, Ren HN, Yan SW, Han Y, et al. Characterization of a Trichinella spiralis putative serine protease Study of its potential as serodiagnostic tool. PloS Negl Trop Dis. 2018;12:e0006485.

40. Wang B, Wang ZQ, Jin J, Ren HJ, Liu LN, Cui J. Cloning, expression and characterization of a Trichinella spiralis serine protease gene encoding a 35.5 kDa protein. Exp Parasitol. 2013;134:148-54.
41. Long SR, Wang ZQ, Jiang P, Liu RD, Qi X, Liu P, et al. Characterization and functional analysis of Trichinella spiralis Nudix hydrolase. Exp Parasitol. 2015:159:264-73.

42. Liu CY, Song YY, Ren HN, Sun GG, Liu RD, Jiang P, et al. Cloning and expression of a Trichinella spiralis putative glutathione S-transferase and its elicited protective immunity against challenge infections. Parasit Vectors. 2017:10:448

43. Song YY, Zhang Y, Ren HN, Sun GG, Qi X, Yang F, et al. Characterization of a serine protease inhibitor from Trichinella spiralis and its participation in larval invasion of host's intestinal epithelial cells. Parasit Vectors. 2018;11:499.

44. Gu Y, Sun X, Li B, Huang J, Zhan B, Zhu X. Vaccination with a paramyosinbased multi-epitope vaccine elicits significant protective immunity against Trichinella spiralis infection in mice. Front Microbiol. 2017;8:1475.

45. Long SR, Wang ZQ, Liu RD, Liu LN, Li LG, Jiang P, et al. Molecular identification of Trichinella spiralis nudix hydrolase and its induced protective immunity against trichinellosis in BALB/C mice. Parasit Vectors. 2014;7:600.

46. Cui J, Wang L, Sun GG, Liu LN, Zhang SB, Liu RD, et al. Characterization of a Trichinella spiralis $31 \mathrm{kDa}$ protein and its potential application for the serodiagnosis of trichinellosis. Acta Trop. 2015;142:57-63.

47. Liu LN, Wang ZQ, Zhang X, Jiang P, Qi X, Liu RD, et al. Characterization of Spirometra erinaceieuropaei plerocercoid cysteine protease and potential application for serodiagnosis of sparganosis. PLoS Negl Trop Dis. 2015:9:e0003807.

48. Li LG, Wang ZQ, Liu RD, Yang X, Liu LN, Sun GG, et al. Trichinella spiralis: low vaccine potential of glutathione $S$-transferase against infections in mice. Acta Trop. 2015;146:25-32.

49. Qi X, Yue X, Han Y, Jiang P, Yang F, Lei JJ, et al. Characterization of two Trichinella spiralis adult-specific DNase II and their capacity to induce protective immunity. Front Microbiol. 2018;9:2504.

50. Wang SW, Wang ZQ, Cui J. Protein change of intestinal epithelial cells induced in vitro by Trichinella spiralis infective larvae. Parasitol Res. 2011:108:593-9.

51. Liu RD, Qi X, Sun GG, Jiang P, Zhang X, Wang LA, et al. Proteomic analysis of Trichinella spiralis adult worm excretory-secretory proteins recognized by early infection sera. Vet Parasitol. 2016;231:43-6.

52. Zhang YL, Wang ZQ, Li LG, Cui J. Molecular characterization of Trichinella spiralis aminopeptidase and its potential as a novel vaccine candidate antigen against trichinellosis in BALB/C mice. Parasit Vectors. 2013;6:246.

53. Liu CY, Ren HN, Song YY, Sun GG, Liu RD, Jiang P, et al. Characterization of a putative glutathione S-transferase of the parasitic nematode Trichinella spiralis. Exp Parasitol. 2018;187:59-66.

54. Liu P, Cui J, Liu RD, Wang M, Jiang P, Liu LN, et al. Protective immunity against Trichinella spiralis infection induced by Ts Nd vaccine in mice. Parasit Vectors. 2015;8:185.

55. Ren HN, Guo KX, Zhang Y, Sun GG, Liu RD, Jiang P, et al. Molecular characterization of a $31 \mathrm{kDa}$ protein from Trichinella spiralis and its induced immune protection in BALB/c mice. Parasit Vectors. 2018;11:625.

56. Sun GG, Lei JJ, Ren HN, Zhang Y, Guo KX, Long SR, et al. Intranasal immunization with recombinant Trichinella spiralis serine protease elicits protective immunity in BABL/c mice. Exp Parasitol. 2019;201:1-10.

57. Xu J, Bai X, Wang LB, Shi HN, Van Der Giessen JWB, Boireau P, et al. Immune responses in mice vaccinated with a DNA vaccine expressing serine protease-like protein from the new-born larval stage of Trichinella spiralis. Parasitology. 2017;144:712-9.

58. Liu RD, Cui J, Wang L, Long SR, Zhang X, Liu MY, et al. Identification of surface proteins of Trichinella spiralis muscle larvae using immunoproteomics. Trop Biomed. 2014:31:579-91.

59. Cui J, Ren HJ, Liu RD, Wang L, Zhang ZF, Wang ZQ. Phage-displayed specific polypeptide antigens induce significant protective immunity against Trichinella spiralis infection in BALB/c mice. Vaccine. 2013;31:1171-7.

60. McVay CS, Bracken P, Gagliardo LF, Appleton J. Antibodies to tyvelose exhibit multiple modes of interference with the epithelial niche of Trichinella spiralis. Infect Immun. 2000;68:1912-8.

61. Long Y, Cao BB, Wang YN, Luo DM. Pepsin is a positive regulator of AccathB-2 involved in the rat gut penetration of Angiostrongylus cantonensis. Parasit Vectors. 2016;9:286.

62. Venturiello SM, Malmassari SL, Costantino SN, Nunez GG. Cytotoxicityblocking antibodies in human chronic trichinellosis. Parasitol Res. 2000;86:762-7. 
63. Cui J, Li LG, Jiang P, Liu RD, Yang X, Liu LN, et al. Biochemical and functional characterization of the glutathione S-transferase from Trichinella spiralis. Parasitol Res. 2015;114:2007-13.

64. Watanabe N, Bruschi F, Korenaga M. IgE: a question of protective immunity in Trichinella spiralis infection. Trends Parasitol. 2005;21:175-8.

65. Matsumoto M. In vivo assay of IgE activities on the expulsion of intestinal adult worms. Parasitol Int. 2016;65:506-9.

66. Bell RG. The generation and expression of immunity to Trichinella spiralis in laboratory rodents. Adv Parasitol. 1998:41:149-217.

67. Gurish MF, Bryce PJ, Tao H, Kisselgof AB, Thornton EM, Miller HR, et al. IgE enhances parasite clearance and regulates mast cell responses in mice infected with Trichinella spiralis. J Immunol. 2004;172:1139-45.

68. Falduto GH, Vila CC, Saracino MP, Calcagno MA, Venturiello SM. Trichinella spiralis: killing of newborn larvae by lung cells. Parasitol Res. 2015;114:679-85.

69. Yang Y, Bai X, Li C, Tong M, Zhang P, Cai W, et al. Molecular characterization of fructose-1,6-bisphosphate aldolase from Trichinella spiralis and its potential in inducing immune protection. Front Cell Infect Microbiol. 2019;9:122
70. Liu P, Wang ZQ, Liu RD, Jiang P, Long SR, Liu LN, et al. Oral vaccination of mice with Trichinella spiralis nudix hydrolase DNA vaccine delivered by attenuated Salmonella elicited protective immunity. Exp Parasitol. 2015;153:29-38.

71. Yang F, Yang DQ, Song YY, Guo KX, Li YL, Long SR, et al. In vitro silencing of serine protease inhibitor suppresses Trichinella spiralis invasion, development and fecundity. Parasitol Res. 2019:118:2247-55.

72. Parkhouse RM, Ortega-Pierres G. Stage-specific antigens of Trichinella spiralis. Parasitology. 1984;88:623-30.

\section{Publisher's Note}

Springer Nature remains neutral with regard to jurisdictional claims in published maps and institutional affiliations.
Ready to submit your research? Choose BMC and benefit from:

- fast, convenient online submission

- thorough peer review by experienced researchers in your field

- rapid publication on acceptance

- support for research data, including large and complex data types

- gold Open Access which fosters wider collaboration and increased citations

- maximum visibility for your research: over $100 \mathrm{M}$ website views per year

At BMC, research is always in progress.

Learn more biomedcentral.com/submissions 